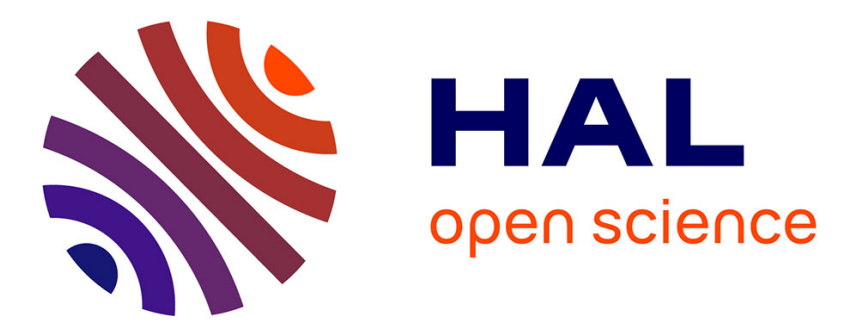

\title{
Nanostructure and photocatalytic properties of TiO2 films deposited at low temperature by pulsed PECVD
}

D. Li, S. Bulou, N. Gautier, S. Elisabeth, A. Goullet, M. Richard-Plouet, P.

Choquet, A. Granier

\section{- To cite this version:}

D. Li, S. Bulou, N. Gautier, S. Elisabeth, A. Goullet, et al.. Nanostructure and photocatalytic properties of TiO2 films deposited at low temperature by pulsed PECVD. Applied Surface Science, 2019, 466, pp.63-69. 10.1016/j.apsusc.2018.09.230 . hal-01972335

\section{HAL Id: hal-01972335 \\ https://hal.science/hal-01972335}

Submitted on 30 Apr 2020

HAL is a multi-disciplinary open access archive for the deposit and dissemination of scientific research documents, whether they are published or not. The documents may come from teaching and research institutions in France or abroad, or from public or private research centers.
L'archive ouverte pluridisciplinaire HAL, est destinée au dépôt et à la diffusion de documents scientifiques de niveau recherche, publiés ou non, émanant des établissements d'enseignement et de recherche français ou étrangers, des laboratoires publics ou privés.

\section{(c)(1)}

Distributed under a Creative Commons Attribution| 4.0 International License 


\title{
Nanostructure and photocatalytic properties of $\mathrm{TiO}_{2}$ films deposited at low temperature by pulsed PECVD
}

\author{
D. Li ${ }^{\text {a,c }}$, S. Bulou ${ }^{\text {b }}$, N. Gautier ${ }^{\text {a }}$, S. Elisabeth ${ }^{\text {a }}$, A. Goullet ${ }^{\text {b }}$, M. Richard-Plouet ${ }^{\text {, }}$ P. \\ Choquet $^{\text {b }}$, A. Granier ${ }^{\text {a }}$ \\ ${ }^{a}$ Institut des Matériaux Jean Rouxel (IMN), Université de Nantes, CNRS, 2 rue de la Houssinière, BP 32229 \\ 44322 Nantes, France \\ ${ }^{b}$ Luxembourg Institute of Science and Technology, 5 avenue des Hauts-Fourneaux, L-4362 Esch-sur-Alzette, \\ Luxembourg, \\ ${ }^{c}$ College of Mechanical Engineering, Yangzhou University, Yangzhou 225127, China
}

\begin{abstract}
The nanostructure and photocatalytic properties of $\mathrm{TiO}_{2}$ thin films deposited by PECVD on silicon substrates were investigated. The films were grown at low temperature $\left(<120^{\circ} \mathrm{C}\right)$ in an rf inductively coupled oxygen/titanium tetraisopropoxide plasma, in continuous and pulsed modes with different plasma-on time (via variation of the duty cycle, DC). All the films exhibit nano-columnar structures, but the reduction of plasma-on time by decreasing the duty cycle for pulsed mode leads to a more homogenous morphology with a diminished column size, and a decrease in the surface roughness. $\mathrm{TiO}_{2}$ layers containing a high amount of anatase were grown at substrate temperatures less than $100{ }^{\circ} \mathrm{C}$ corresponding to $\mathrm{DC} \geq 40 \%$, then the crystallization was hindered with the decrease of DC, even inducing amorphous films for DC $\leq 10 \%$. Moreover, the films deposited below $100{ }^{\circ} \mathrm{C}$ with deposition conditions where $50 \% \leq$ DC $\leq 75 \%$ were shown to present a high photocatalytic activity, likely due to the presence of anatase crystalline nanocolumns at the surface.
\end{abstract}


Keywords: PECVD; pulsed plasma; $\mathrm{TiO}_{2}$; anatase; TEM; photocatalytic activity.

\section{Introduction}

$\mathrm{TiO}_{2}$ thin films have attracted intensive research as photocatalysts for their advantages in chemical stability, non-toxicity, commercial availability at a low cost and high photocatalytic activity [1-3]. The $\mathrm{TiO}_{2}$ properties are due to its crystalline form which is mainly encountered as three phases including tetragonal anatase, tetragonal rutile and orthorhombic brookite [4]. $\mathrm{TiO}_{2}$ exhibits different band gap energies for its different phases, viz. anatase $(3.2 \mathrm{eV})$, rutile $(3 \mathrm{eV})$ and brookite $(3.1 \mathrm{eV})[5-8]$. In addition to the effect of $\mathrm{TiO}_{2}$ crystallization, some other essential factors such as grain size, preferred grain orientation, presence of structure defects and capability to absorb hydroxyl groups in the initial phase of excitation may also affect the photocatalytic activity [9-11]. Powders suspended in polluted solution due to their higher specific area may lead to more efficient photocatalytic properties, however films do not require filtering to be recovered after the volume to be depolluted has been treated. These films can be prepared by using different methods including sol-gel method [12-19], which is the most often used to synthesize $\mathrm{TiO}_{2}$ thin films for photocatalytic applications. However other strategies were also largely investigated, such as liquid phase deposition [20], magnetron sputtering [21-23], atomic layer deposition [24], spray pyrolysis [25], chemical vapor deposition [26], metalorganic chemical vapor deposition [27] and plasma enhanced chemical vapor deposition (PECVD) [28-32]. Each method may lead to the growth of particular structure and film morphology, which may be quite distinctive and very difficult to repeat with another method. These particularities, on the other hand, may have a substantial effect on the overall photocatalytic activity of the material.

In the literature, titanium dioxide in anatase is generally reported to be obtained at high temperature, in the range of $400-600{ }^{\circ} \mathrm{C}$ [33]. However, plasma assisted deposition 
(magnetron sputtering, PECVD) is known to allow decreasing the deposition temperature of many materials due to the bombardment of the growing film by energetic neutral and charged species. Nevertheless, in the case of $\mathrm{TiO}_{2}$, the deposition of anatase thin films by magnetron sputtering or PECVD below $150{ }^{\circ} \mathrm{C}$ was reported by only few authors [23, 34].

In our previous studies, PECVD processes were used to yield some nanocolumnar structures with different phases including amorphous, anatase and rutile [35-36]. Actually these processes exhibit favorable features such as low deposition temperature, good film adhesion, high purity, good step coverage and easy control of reaction parameters [28, 37]. Enhancement of chemical reactions by means of low temperature plasma has been known and used for many years. In particular, some new nanostructured materials that cannot be obtained under equilibrium conditions could be prepared using chemical reaction under non equilibrium conditions [38-41], and in the area of property-altering surface coatings [42-43]. For photocatalytic applications, in order to reduce the substrate temperature during deposition while maintaining a sufficient energy input to obtain $\mathrm{TiO}_{2}$ in crystallized form, the PECVD deposition can be controlled in pulsed plasma mode. In this mode, the electrical power is periodically applied to the gas, so that two times are then defined: the discharge time, when the power is applied for a time denoted $\mathrm{T}_{\mathrm{on}}$, and the post-discharge time, when the power is switched off for a time denoted $\mathrm{T}_{\text {off. }}$ Varying the plasma-on time to the period time has two important effects [44-45]: (1) to vary the mean power coupled to the plasma and hence the deposition temperature; (2) to allow the control of the ion to neutral flux ratio, which strongly influences the nanostructure and crystallinity.

In this work, we investigate the influence of the duty cycle (DC), defined as the discharge time to the period ratio, on the structural and photocatalytic properties of the $\mathrm{TiO}_{2}$ films 
deposited on silicon substrates in pulsed PECVD mode. The latter are also compared to the film deposited in continuous mode. The aim is both to gain insight into the influence of pulsed parameters on the structure of the deposited films by transmission electron microscopy (TEM), scanning electron microscopy (SEM), atomic force microscopy (AFM), X-ray diffraction (XRD), Raman spectroscopy and to deposit $\mathrm{TiO}_{2}$ films with high photocatalytic activity at low temperature (typically below $100^{\circ} \mathrm{C}$ ).

\section{Experimental}

In this study, $\mathrm{TiO}_{2}$ films were deposited on silicon (100) substrate (Si, supplied by Codex International, purity $>99.9999999 \%$, CAS Number: 7440-21-3) using a low pressure high density radiofrequency $(13.56 \mathrm{MHz})$ plasma process which is made of a plasma source connected to the diffusion chamber where a substrate is positioned. The rf inductively coupled plasma (ICP) source was generated by applying an $\mathrm{rf}$ power $(400 \mathrm{~W})$ to an external helicon antenna. Oxygen was introduced at the top of the plasma source. Titanium tetraisopropoxide $\left[\mathrm{Ti}\left(\mathrm{OC}_{3} \mathrm{H}_{7}\right)_{4}\right.$, TTIP, purity 99.999\%, CAS Number: 546-68-9, supplied by Sigma Aldrich Ltd.], used as the titanium precursor, was injected into the diffusion chamber through a dispersal ring above the substrate holder. The flow rates of pure TTIP and oxygen were fixed at $0.24 \mathrm{sccm}$ and $16 \mathrm{sccm}$, respectively, which corresponds to a 98.5:1.5 $\mathrm{O}_{2} /$ TTIP mixture, while the total working pressure was fixed at $0.4 \mathrm{~Pa}$. The $\mathrm{O}_{2} / \mathrm{TTIP}$ plasmas can be operated either in continuous $(\mathrm{CW})$ or pulsed mode. In this study the frequency was fixed at $1 \mathrm{kHz}$ and the duty cycle (DC) was varied from 10 to $75 \%$ by tuning the $\mathrm{T}_{\text {on }}$ time. The thickness lies between 250 and $300 \mathrm{~nm}$ for all deposited films. The substrate temperature was measured using temperature sensitive labels stuck on the back side of the Si substrates [46]. It was measured to be around $120{ }^{\circ} \mathrm{C}$ in continuous (CW) standard plasma conditions and was 
shown to be decreased in the pulsed mode down to $80{ }^{\circ} \mathrm{C}$ for $\mathrm{DC}=50 \%$ and below $50{ }^{\circ} \mathrm{C}$ for $\mathrm{DC}=25 \%$. The deposition parameters are summarized in Table 1.

Table 1. Growth conditions of $\mathrm{TiO}_{2}$ films using the pulsed PECVD system.

\begin{tabular}{ll}
\hline rf power coupled to the ICP source & $400 \mathrm{~W}$ \\
Working pressure & $0.4 \mathrm{~Pa}$ \\
Flow rate of TTIP & $0.24 \mathrm{sccm}$ \\
Flow rate of $\mathrm{O}_{2}$ & $16 \mathrm{sccm}$ \\
Pulsed mode frequency & $1 \mathrm{kHz}$ \\
Duty cycle $(\mathrm{DC})$ for pulsed mode & $10 \%, 25 \%, 40 \%, 50 \%, 75 \%, \mathrm{CW}$ \\
Substrate temperature $\left( \pm 5^{\circ} \mathrm{C}\right)$ & $<50,<50,50,80,90,120$ \\
Substrate & $\mathrm{Si}(100)$ \\
\hline
\end{tabular}

The film morphology was observed by SEM using a JEOL-type JSM 7600F, operating at 10 kV. TEM analysis was performed using a Hitachi H9000-NAR microscope ( $\mathrm{LaB}_{6}$ filament, $300 \mathrm{kV}$, point to point resolution: $0.18 \mathrm{~nm}$ ). Cross-section TEM samples were prepared by tripod polishing and afterwards by $\mathrm{Ar}^{+}$ion polishing using Gatan precision ion polishing system (PIPS). The crystalline nature of all the films was determined by X-Ray diffraction (XRD) and Raman spectroscopy. XRD measurements were carried out on a Siemens D8 using $\mathrm{Cu} \mathrm{K} \alpha$ radiation $(\mathrm{K} \alpha=1.5406 \AA)$ operating in $\theta / 2 \theta$ configuration, in the $2 \theta$ range of 20 $60^{\circ}$, with a step of $0.03^{\circ}$ and a dwell of $15 \mathrm{~s} / \mathrm{step}$. $\mathrm{TiO}_{2}$ anatase peaks were attributed thanks to JCPDS file number 89-4921. The Raman spectra were recorded with a Renishaw inVia micro-Raman spectrometer at an excitation wavelength of $532 \mathrm{~nm}$ with a laser power of approximately $0.44 \mathrm{~mW}$ focused on a $1 \mu \mathrm{m}^{2}$ spot. The film surface topography was observed by atomic force microscopy (AFM, NanoWizard II, JPK Instruments) in the contact mode. The photocatalytic activity of the as-deposited $\mathrm{TiO}_{2}$ films was studied by measuring stearic acid (SA) decomposition under UV exposure (Herolab UV-8 SL, $254 \mathrm{~nm}, 8 \mathrm{~W}$ ). In order to deposit stearic acid on the entire surface of the sample, it was diluted in methanol $\left(0.02 \mathrm{~mol} \mathrm{~L}^{-}\right.$ $\left.{ }^{1}\right)$ and deposited by spin coating. 10 microliters were deposited on the coatings $\left(1 \mathrm{~cm}^{2}\right)$ and 
spin-coated for 30 seconds at $10000 \mathrm{rpm}$. The samples were then stored in dark in a black box for at least 3 hours before being exposed to the light source. The samples were then illuminated by an UV lamp. The UV lamp (Herolab UV-8 SL, $254 \mathrm{~nm}, 8 \mathrm{~W}$ ) was positioned $20 \mathrm{~cm}$ above the samples, corresponding to a calculated irradiance of ca. $0.38 \mathrm{~mW} \mathrm{~cm}^{-2}$ (i.e. $4.9 \times 10^{14}$ photons. $\mathrm{s}^{-1} \mathrm{~cm}^{-2}$ ) illuminating the samples surface [47].

The decomposition of the stearic acid was assessed using FTIR spectroscopy (Bruker VERTEX 70 in transmission) by measuring the integrated area of absorption bands in the range 2800-3000 $\mathrm{cm}^{-1}$ (C-H stretching modes of the stearic acid). The photodegradation efficiency was evaluated through the monitoring of this absorption band area as a function of illumination duration. The linear regression of the corresponding degradation curves gives a photocatalytic efficiency $\left(\mathrm{cm}^{-1} \mathrm{~h}^{-1}\right)$.

Besides, the FTIR absorption in the range $2800-3000 \mathrm{~cm}^{-1}$ is linked to the quantity of SA by a conversion factor $\delta$, which gives an equivalency between a number of molecules of SA per $\mathrm{cm}^{2}$ and an integrated FTIR area value of $1 \mathrm{~cm}^{-1}$. A conversion factor value of $\delta=$ $9.7 \times 10^{15}$ molecules of SA $\mathrm{cm}^{-2}$ per $\mathrm{cm}^{-1}$ of FTIR absorption is used in this article [48]. This allows us to calculate an UV light activity $\mathrm{R}_{\mathrm{SA}}$ defined as the number of molecules $\mathrm{cm}^{-2}$ of SA degraded per second. 


\section{Results}

\subsection{Film morphology}
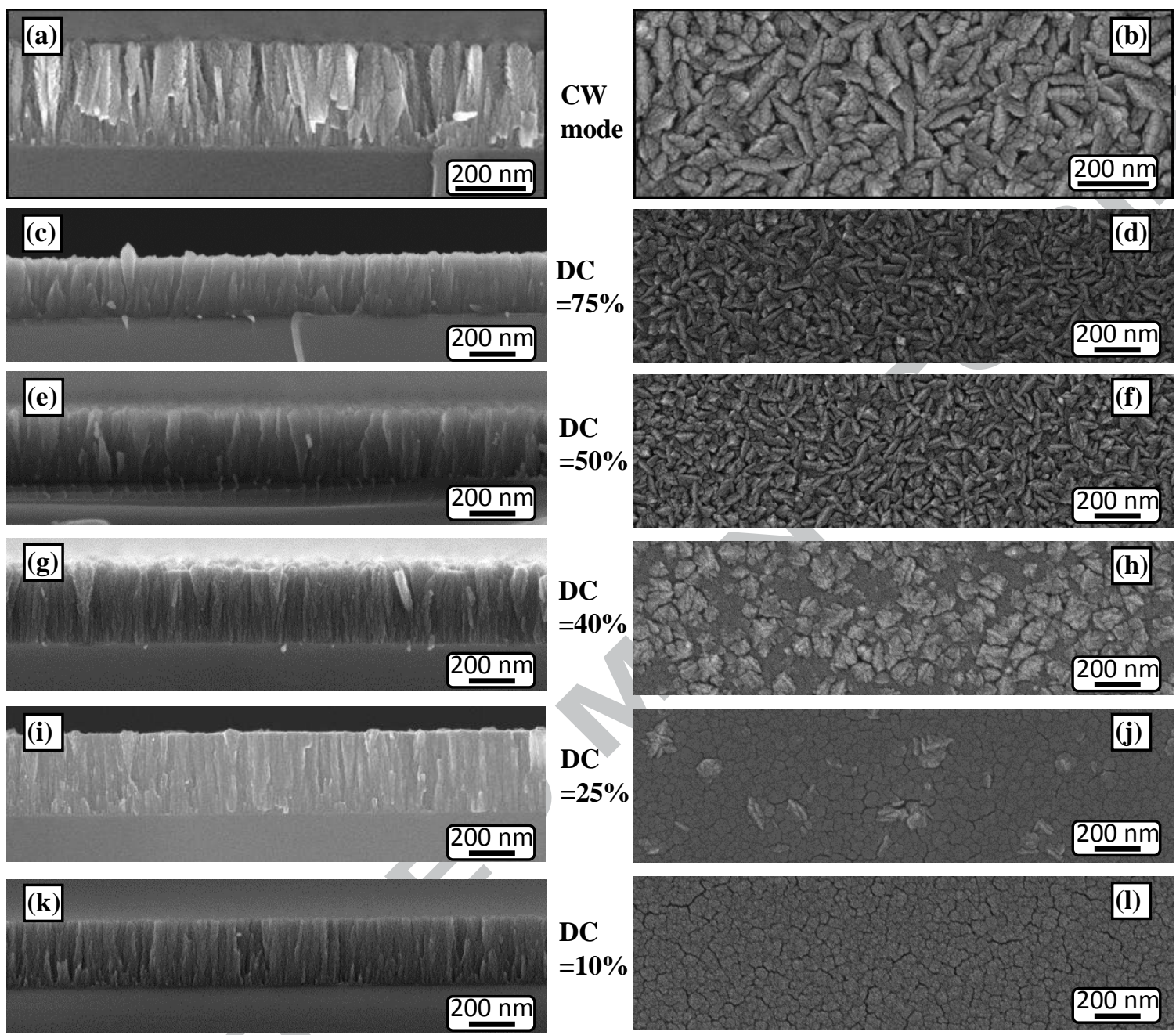

Fig. 1. SEM micrographs of the $\mathrm{TiO}_{2}$ films deposited with different duty cycles for pulsed and continuous mode (100\%). (a, b) continuous mode, (c, d) DC $=75 \%$, (e, f) DC $=50 \%,(g, h) D C=40 \%,(i, j) D C=25 \%,(k, l) D C$ $=10 \%,(\mathrm{a}, \mathrm{c}, \mathrm{e}, \mathrm{g}, \mathrm{i}, \mathrm{k})$ SEM side-views, (b, d, f, h, j, l) SEM top-views.

SEM micrographs including side-views and top-views of the $\mathrm{TiO}_{2}$ films deposited in continuous mode and in pulsed mode for different duty cycles are displayed in Fig. 1. All the films exhibit columnar structures, but it seems that the column size can be decreased as the duty cycle is reduced which can be identified by TEM in details. The CW mode leads to a typical morphology on Si substrate in agreement with previous studies [35], which is the gradient columnar structure including a dense sublayer at the interface and a disordered 
columnar top layer. The morphologies for the films grown in the pulsed mode with DC $\geq 40 \%$ retain the same gradient columnar structure, but the degree of homogeneity in the growth direction is improved as DC is decreased. Moreover, when DC $<40 \%$, the columns appear more organized and the whole morphology seems to be homogenous along the growth direction.

The evolution of cross-sectional morphology is also reflected in the surface topography (see Fig. 2), for the films deposited at DC $>40 \%$, the top surfaces are quite rough because of the disordered columns leading to some clustering of grains till the surface. Moreover, the RMS roughness value decreases with $\mathrm{DC}$, from $9.0 \mathrm{~nm}$ for $\mathrm{CW}$ mode to $6.0 \mathrm{~nm}$ for $\mathrm{DC}=50 \%$. But in the case of $\mathrm{DC}=40 \%$, the surface topography marks a transition with the gradually disappearance of the clusters leading to an abrupt increase in roughness up to $11.2 \mathrm{~nm}$. The images of the surfaces of the $\mathrm{TiO}_{2}$ films reveal a change from granular clusters to rice-shaped grains as DC is further decreased below $40 \%$, and the grain size is also reduced with DC leading to smoother top surfaces, the roughness is even decreased down to $4.0 \mathrm{~nm}$ for $\mathrm{DC}=25 \%$.
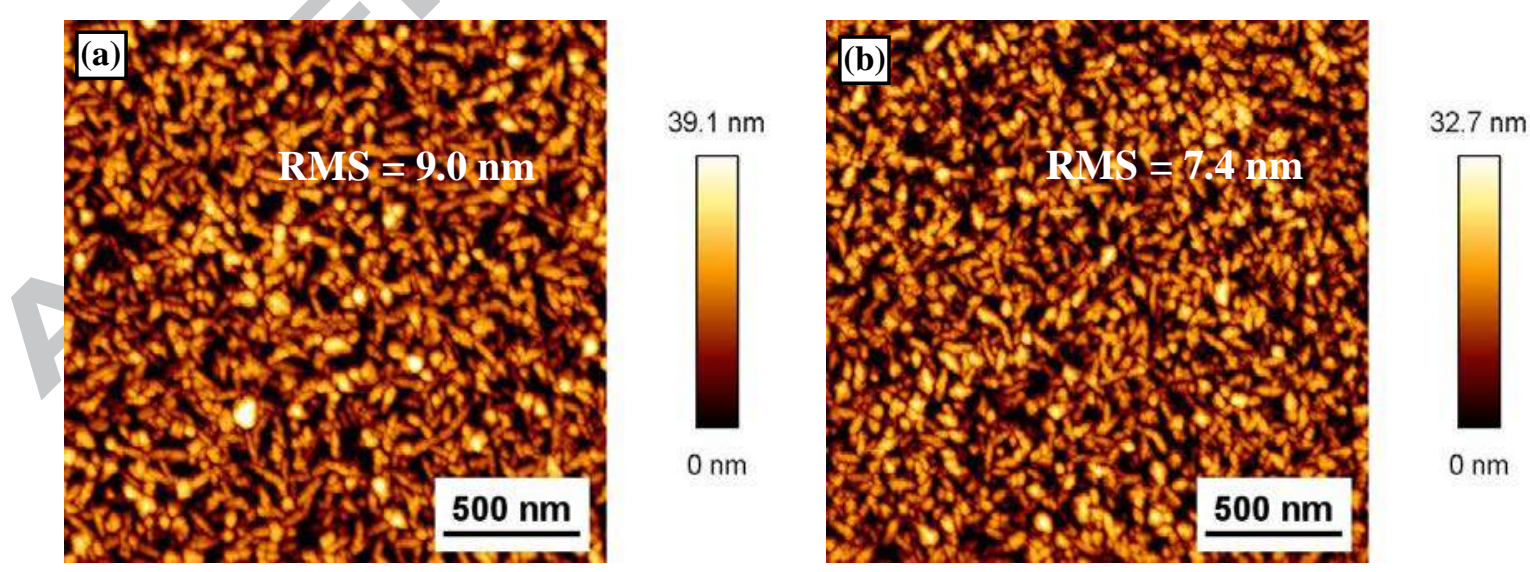

$0 \mathrm{~nm}$ 

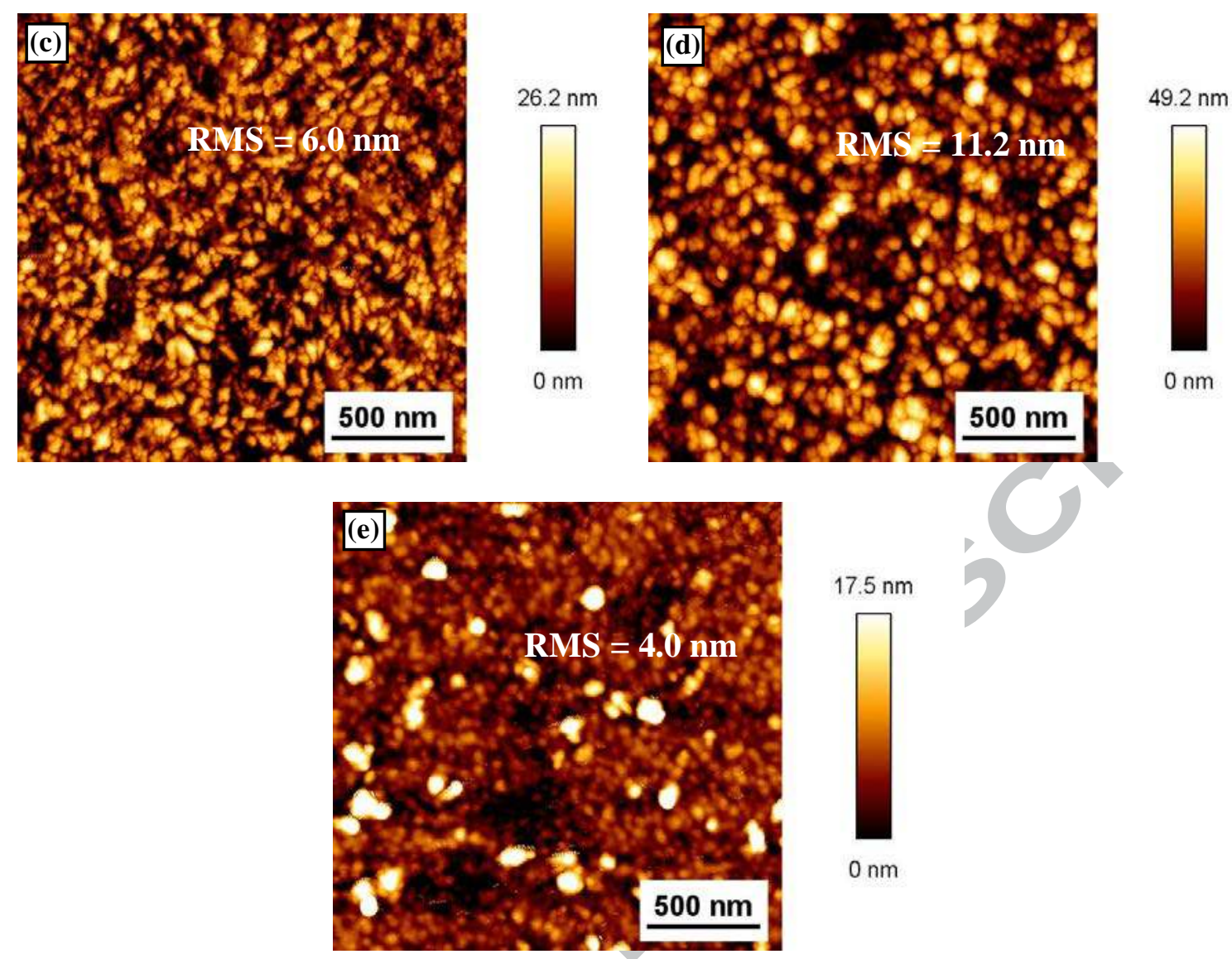

Fig. 2. AFM measurements of the $\mathrm{TiO}_{2}$ films deposited with different duty cycles for pulsed and continuous mode (100\%). (a) continuous mode, (b) $\mathrm{DC}=75 \%$, (c) $\mathrm{DC}=50 \%$, (d) $\mathrm{DC}=40 \%$, (e) $\mathrm{DC}=25 \%$.
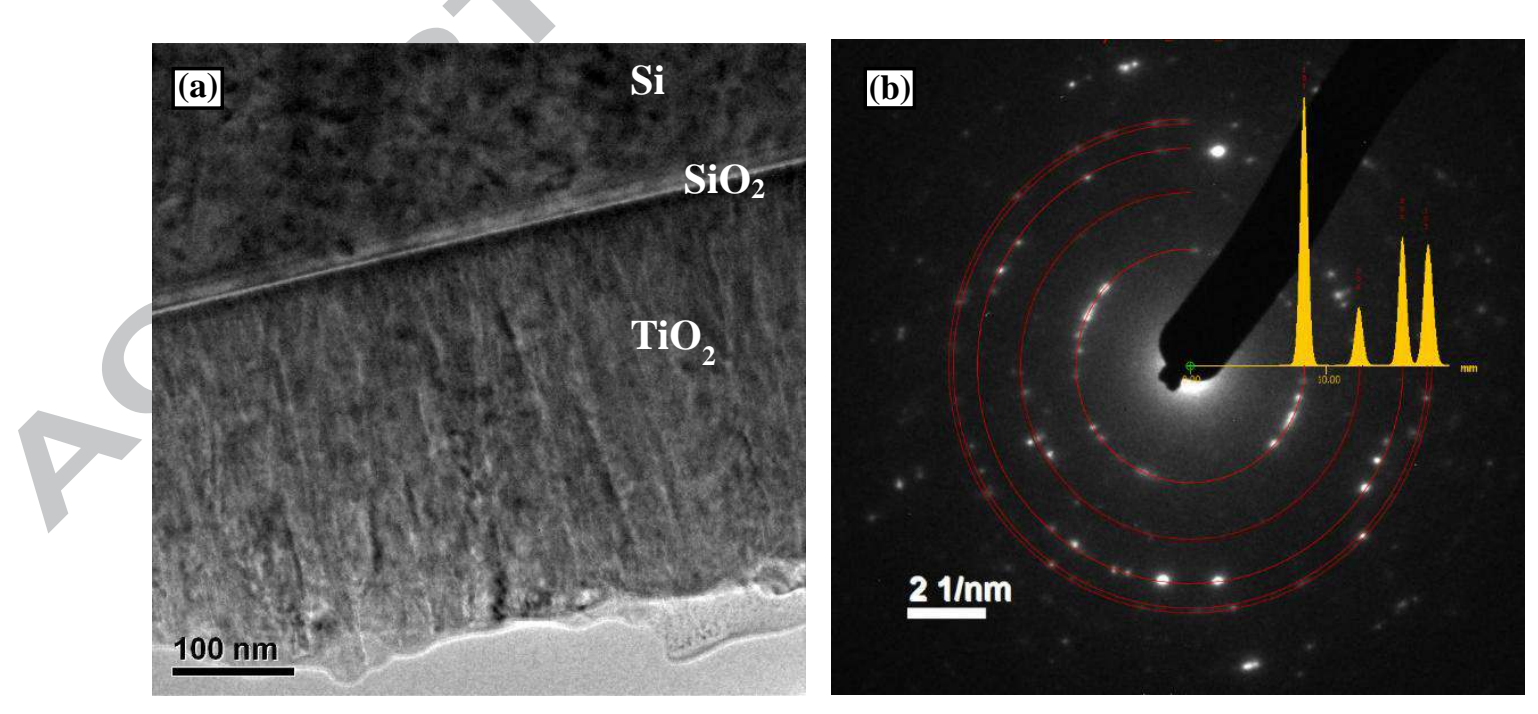

Fig. 3. TEM on the $\mathrm{TiO}_{2}$ film deposited in the continuous mode (CW). (a) The whole film morphology, (b) selected area electronic diffractions (SAED): experimental diffraction of the film and simulation for anatase using JEMS software [49]. 
The TEM image (in Fig. 3) of a 300 nm-thick $\mathrm{TiO}_{2}$ film deposited in the $\mathrm{CW}$ mode on $\mathrm{Si}$ substrate clearly shows a highly crystallized film with a columnar morphology. The interface between the $\mathrm{Si}(100)$ substrate with a $\sim 4 \mathrm{~nm}$ native amorphous $\mathrm{SiO}_{2}$ layer and the polycrystalline $\mathrm{TiO}_{2}$ film was identified in Fig. 3(a). The SAED pattern (Fig. 3(b)) is typical for the anatase phase. The presence of a dense layer topped with a columnar crystallized film is quite consistent with SEM pictures which indicated the presence of a dense film topped with a gradient layer [35].
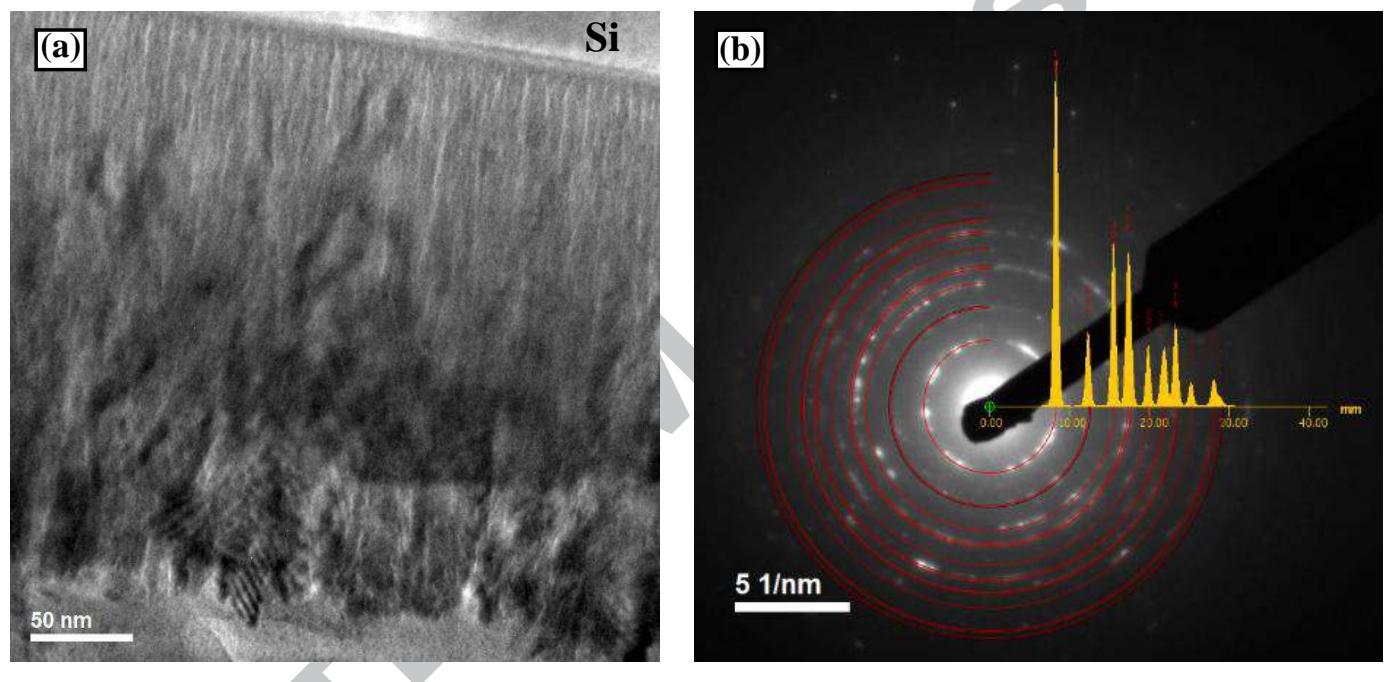

Fig. 4. TEM on the $\mathrm{TiO}_{2}$ film deposited with the duty cycle of $50 \%$ for pulsed mode. (a) The whole film morphology, (b) selected area electronic diffractions (SAED): experimental diffraction of the film and simulation for anatase using JEMS software.

The TEM study of the $\mathrm{TiO}_{2}$ film deposited in the pulsed mode $(\mathrm{DC}=50 \%)$ displayed in Fig. 4 shows that using pulsed plasma allows decreasing the deposition temperature (measured to be less than $80{ }^{\circ} \mathrm{C}$ ) while conserving anatase crystallites (in Fig. 4(b)). Compared to the $\mathrm{CW}$ mode, a similar columnar morphology was observed, but a slight decrease in the column diameter from $\sim 30$ to $\sim 15 \mathrm{~nm}$ was observed for the pulsed mode.

Pulsing the plasma decreases the mean energy transferred to the substrate over a whole period $\left(\mathrm{T}_{\text {on }}+\mathrm{T}_{\text {off }}\right)$ (due to a decrease in the heat and ion fluxes during $\mathrm{T}_{\text {off }}$ ), which affects the surface 
of the growing film and causes a reorganization of the surface atoms. Thus, the reduction of plasma deposition time by decreasing the duty cycle for pulsed mode leads to a more homogenous columnar morphology with a decreased column size and a decrease in the surface roughness.

\subsection{Film crystallization}

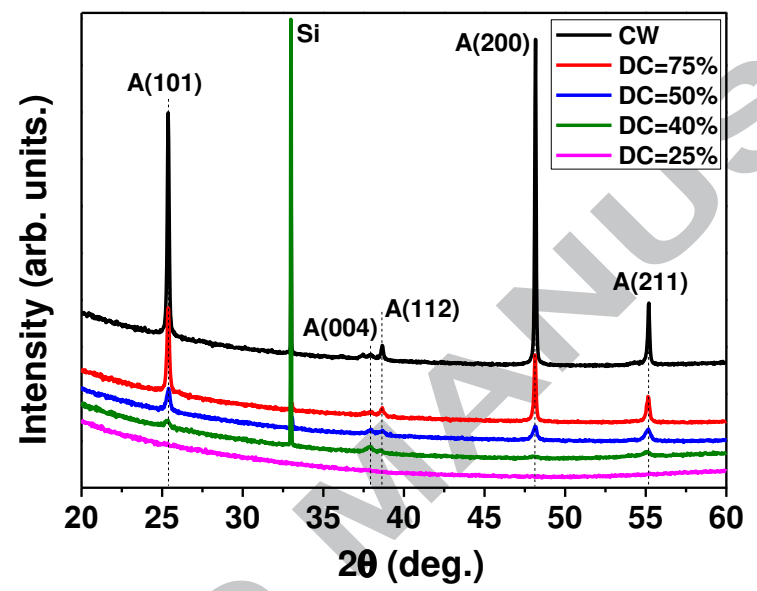

Fig. 5. XRD patterns of the $\mathrm{TiO}_{2}$ films deposited with different duty cycles for pulsed mode and continuous mode.

As can be seen in the XRD patterns displayed in Fig. 5, the as-deposited film in the continuous mode crystallizes in the anatase variety as demonstrated through the appearing of diffraction peaks at $25.5^{\circ}, 37.8^{\circ}, 38.6^{\circ}, 48.1^{\circ}$ and $55.1^{\circ}$, corresponding to lattice planes (101), (004), (112), (200) and (211), respectively. There is a preferential orientation along the (200) direction in the $\mathrm{CW}$ mode, while polycrystalline anatase is produced in pulsed mode. The intensities of the anatase peaks were weakened as DC decreased, and disappeared at DC = $25 \%$, where no peak was detected meaning that the film is amorphous. The crystallization of the films was further investigated by Raman spectroscopy which is very sensitive to low amount of anatase and in our conditions provides more local information than XRD. 


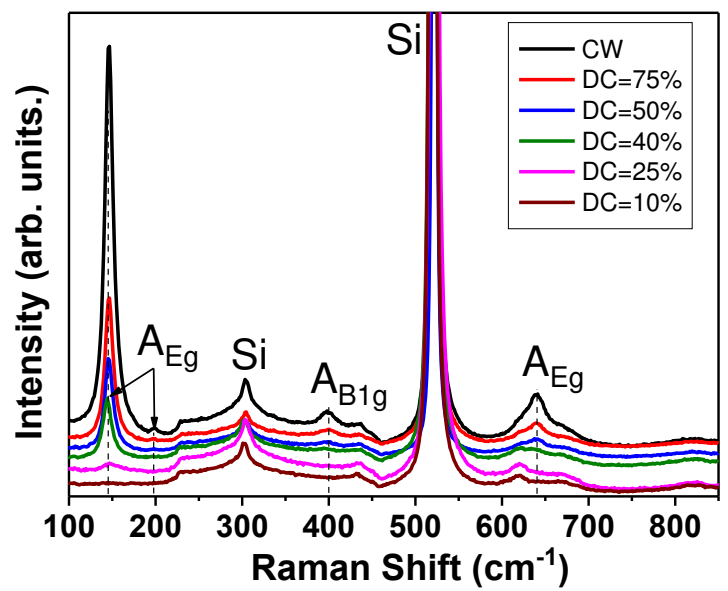

Fig. 6. Raman spectra of the $\mathrm{TiO}_{2}$ films prepared with different duty cycles for pulsed mode and continuous mode $(\mathrm{CW})$.

Fig. 6 shows the evolution of the Raman spectra of the $\mathrm{TiO}_{2}$ films deposited with different duty cycles for pulsed mode and continuous mode. For the $\mathrm{TiO}_{2}$ films grown in the $\mathrm{CW}$ mode and the pulsed mode with $\mathrm{DC} \geq 40 \%$, the spectra exhibit five peaks at $144,198,395,516$ and $640 \mathrm{~cm}^{-1}$ which are characteristic of the anatase phase and assigned to $E_{g}, B_{1 g}, A_{1 g}$ and $E_{g}$ modes [50]. However, in the case of DC $=25 \%$, the characteristic peaks of anatase are very weak in intensity, but the peak at $144 \mathrm{~cm}^{-1}$ is clearly observed which suggests that the film may consist in a small amount of anatase dispersed in an amorphous matrix. For the films deposited at $\mathrm{DC}=10 \%$, the Raman spectra did not show any indication of crystallized $\mathrm{TiO}_{2}$. In the case of $\mathrm{CW}$ mode, ions in the plasma can be continuously generated to participate in the crystallization of the growing film with a simultaneous release of energy which is helpful for the anatase formation. However, in the pulsed mode, the flux and energy of the ion bombardment are no longer generated in post-discharge, which may lead to a reduction in the crystallization rate by increasing the plasma-off time. In addition, the probable phenomenon of hydrolysis of TTIP during post-discharge can also hamper the crystallization, as this reaction is thus carried out in thermodynamic equilibrium and tends to create amorphous $\mathrm{TiO}_{2}$ $[51]$. 
Therefore, a reduction of the amount of the crystallized anatase phase is observed when the duty cycle is decreased. This statement can indicate that the growth of anatase crystalline nanocolumns is directly linked to the deposition period during the plasma on time, independently of the substrate temperature.

\subsection{Photocatalytic activity}

According to the above discussion concerning the influence of pulsed plasmas on the $\mathrm{TiO}_{2}$ film morphology and crystallization, some interesting points about the anatase content, columns size and organization, surface state were demonstrated, which may affect the photocatalytic properties of these $\mathrm{TiO}_{2}$ films. In this work, the photocatalytic activity of thin films was evaluated by monitoring of the degradation of stearic acid under UV light.
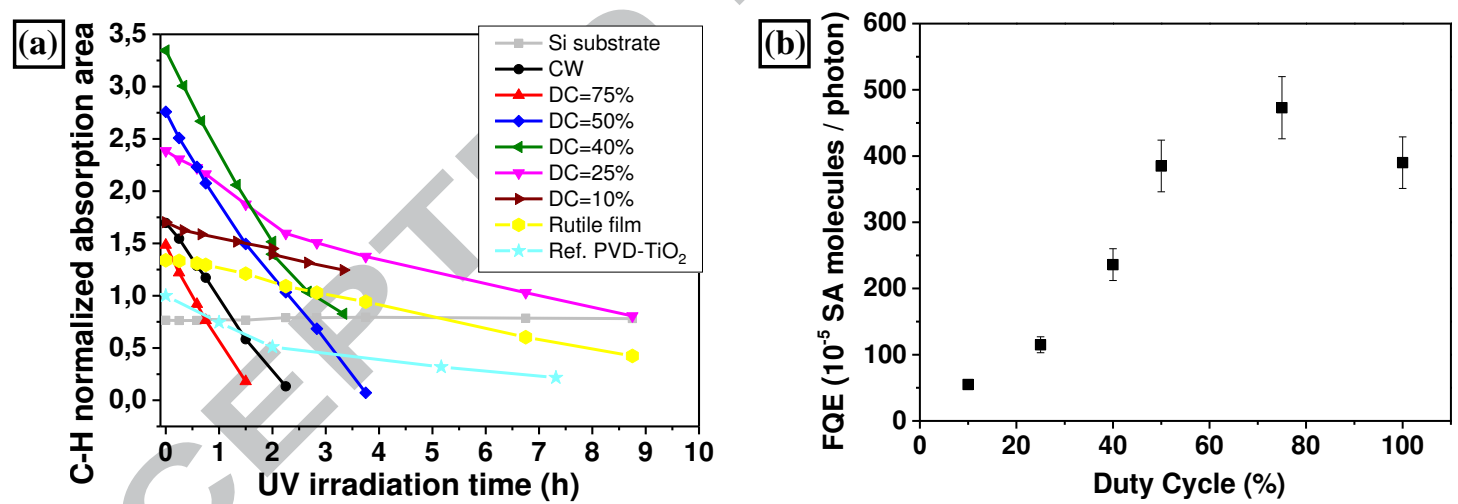

Fig. 7. Evolution of photocatalytic activity for the $\mathrm{TiO}_{2}$ films grown with different duty cycles for pulsed mode and continuous mode (100\%), and compared with the reference $\mathrm{TiO}_{2}$ film deposited by PVD and PECVD-rutile films. (a) C-H absorption integrated area $\left(2800-3000 \mathrm{~cm}^{-1}\right.$ ) versus UV illumination time, (continuous lines are just guidelines to get a better view of the evolutions) (b) Formal Quantum Efficiency for SA molecules calculated from SA degradation rate as a function of the duty cycles.

Fig. 7 presents the evolution of the integrated area of the FTIR absorption band in the range $2800-3000 \mathrm{~cm}^{-1}$ as a function of the exposure duration to UV illumination on the $\mathrm{TiO}_{2}$ films deposited in continuous and pulsed modes. These measurements were also compared to 
photocatalytic performance (with the same measuring device) of bare silicon substrate, PECVD-grown rutile films [35] and $2 \mu \mathrm{m} \mathrm{TiO}_{2}$ film obtained by magnetron sputtering (PVD) at $250{ }^{\circ} \mathrm{C}$ [52]. One can note that the silicon substrate has no photocatalytic activity (as expected), whereas the films presented in this work all exhibit a decrease of the SA quantity when illuminated by UV light.

In order to compare with available literature data, the formal quantum efficiency (FQE) for SA is calculated [48] and presented in Fig. 7(b). The FQE is calculated as the number of SA photodegraded by the incident photons (see eq. 1). The slope of the degradation curve of SA, $\mathrm{R}_{\mathrm{SA}}$ and FQE for the films deposited under different conditions are shown in Table 2.

(eq. 1)

Table 2. Evolution of the $\mathrm{SA}$ degradation rate, $\mathrm{R}_{\mathrm{SA}}$ and $\mathrm{FQE}$ for the $\mathrm{TiO}_{2}$ films grown with different duty cycles for pulsed mode and continuous mode (100\%).

\begin{tabular}{|c|c|c|c|}
\hline Duty cycle & $\begin{array}{c}\text { SA degradation rate } \\
\left(\mathrm{h}^{-1}\right)\end{array}$ & $\begin{array}{l}\mathrm{R}_{\mathrm{SA}}(\mathrm{SA}, 254 \mathrm{~nm}) \\
\left(\text { molecules } \mathrm{cm}^{-2} \mathrm{~s}^{-1}\right)\end{array}$ & $\begin{array}{c}\mathrm{FQE}(\mathrm{SA}, 254 \mathrm{~nm}) \\
\left(10^{-5} \text { molecules/photon }\right)\end{array}$ \\
\hline $100 \%(\mathrm{CW})$ & $0.71 \pm 0.7$ & $(1.9 \pm 0.2) \times 10^{12}$ & $390 \pm 39$ \\
\hline $75 \%$ & $0.86 \pm 0.9$ & $(2.3 \pm 0.3) \times 10^{12}$ & $473 \pm 47$ \\
\hline $50 \%$ & $0.7 \pm 0.7$ & $(1.9 \pm 0.2) \times 10^{12}$ & $385 \pm 39$ \\
\hline $40 \%$ & $0.43 \pm 0.4$ & $(1.2 \pm 0.1) \times 10^{12}$ & $236 \pm 24$ \\
\hline $25 \%$ & $0.21 \pm 0.2$ & $(5.7 \pm 0.6) \times 10^{11}$ & $115 \pm 12$ \\
\hline $10 \%$ & $0.1 \pm 0.01$ & $(2.7 \pm 0.3) \times 10^{11}$ & $55 \pm 6$ \\
\hline
\end{tabular}

The reproducibility of photocatalytic activity measurements was confirmed for several samples deposited for $\mathrm{DC}=100,75$ and $50 \%$.

The photodegradation efficiency of $\mathrm{TiO}_{2}$ films containing anatase deposited at $\mathrm{DC}=100 \%$, $75 \%$ and $50 \%$ exhibits very high values, with FQE equal to $390 \times 10^{-5}, 473 \times 10^{-5}$ and $385 \times 10^{-5}$ 
molecules/photon respectively. These values are very good as they surpass the FQE of some reference films such as $\mathrm{P} 25 \mathrm{TiO}_{2}$ and Pilkington Activ thin films, which exhibit FQE values of $256 \times 10^{-5}$ and $10 \times 10^{-5}$ respectively [53].

Nevertheless, photocatalysis is somehow dependent on the coating thickness. Indeed, thicker films induced a higher probability of producing reactive species that participate to catalytic processes. In this article, thin films have a thickness of ca. $250 \mathrm{~nm}$, whereas in the article of A. Mills et al [53], P25 $\mathrm{TiO}_{2}$ and Pilkington Activ have a thickness of $90 \mathrm{~nm}$ and $15 \mathrm{~nm}$ respectively. One can note the slightly higher photocatalytic activity of the samples obtained at $\mathrm{DC}=50 \%, 75 \%$ and $100 \%$ which might be due to more anatase content and higher surface area, induced by smaller column size and higher roughness. It is then noted that the photocatalytic activity decreases when DC decreases reaching $\mathrm{FQE}=236 \times 10^{15}, 115 \times 10^{15}$ and $55 \times 10^{15}$ molecules per photon for $\mathrm{DC}=40 \%, 25 \%$ and $10 \%$ respectively. Although these films have lower photoactivity, their efficiency is still good especially when considering the very low substrate temperature $\left(<50^{\circ} \mathrm{C}\right)$ during deposition.

$\mathrm{TiO}_{2}$ layers deposited for $\mathrm{DC} \geq 50 \%$ contain a significant amount of anatase and present the highest photocatalytic activity. Although the $\mathrm{TiO}_{2}$ layer grown at $\mathrm{DC}=40 \%$ has a quite rough top surface, the crystalline anatase content detected by Raman scattering and XRD is high enough to lead to a lower but still significant photocatalytic activity. In the cases of DC $=25$ and $10 \%, \mathrm{TiO}_{2}$ layers have a reduced but still significant conversion rate which is higher than the PVD-deposited anatase at $250{ }^{\circ} \mathrm{C}$ [52]. Indeed, the $\mathrm{R}_{\mathrm{SA}}$ of the film obtained at $\mathrm{DC}=10 \%$, at a temperature $<50{ }^{\circ} \mathrm{C}$ is comparable to other films obtained using an atmospheric pressure PECVD process with substrate temperature around $100{ }^{\circ} \mathrm{C}$ [54]. Moreover, the rutile $\mathrm{TiO}_{2}$ film deposited by PECVD shows a rather poor photodegradation efficiency.

This study has demonstrated that it is possible to deposit $\mathrm{TiO}_{2}$ layers with high photocatalytic activity at temperatures below $100{ }^{\circ} \mathrm{C}(50 \% \leq \mathrm{DC} \leq 75 \%)$. This therefore opens up interesting 
prospects for the deposition of photocatalytic layers, for example on flexible polymer substrates.

\section{Conclusions}

Highly efficient photocatalytic anatase nanocolumnar $\mathrm{TiO}_{2}$ thin films were successfully deposited by pulsed-PECVD process at relatively low temperature less than $100{ }^{\circ} \mathrm{C}$ on $\mathrm{Si}$ substrate. The effect of plasma-off time by tuning the duty cycle of pulsed mode was investigated on $\mathrm{TiO}_{2}$ thin films in view of improving their photocatalytic properties. The efficient photocatalytic property of such a film depends on the presence of the anatase phase at its surface and also its roughness and microstructure. At a duty cycle between $40 \%$ and $100 \%$, the bombardment of the particles at the substrate is strong enough for inducing mobility of surface particles, promoting the formation of crystalline anatase $\mathrm{TiO}_{2}$ films with disordered columnar morphologies. The photocatalytic activity for these films is very high. As DC is decreased below $40 \%$, the accumulation of impact energy and heat is insufficient, leading to the formation of a surface including only a small amount of anatase embedded in an amorphous film, which has relatively smooth surface and homogeneous columns along the growth direction. Thus the photocatalytic activity is reduced, but is still significant regarding the low substrate temperature.

\section{Acknowledgments}

Acknowledgements for the master students: Theo Leclerq (mainly) for this paper. The work of Dayu Li is supported by the National Natural Science Foundation of China (51602279), High-end Talents and Young Backbone Teacher Project of Yangzhou University.

\section{References}


[1]. M. Nasr, C. Eid, R. Habchi, P. Miele, M. Bechelany, Recent progress on titanium dioxide nanomaterials for photocatalytic applications, ChemSusChem 11 (2018) 1-26.

[2]. L. Chen, M.E. Graham, G. Li, K.A. Gray, Fabricating highly active mixed phase $\mathrm{TiO}_{2}$ photocatalysts by reactive DC magnetron sputter deposition, Thin Solid Films 515 (2006) 1176-1181.

[3]. C.H. Lu, W.H. Wu, R.B. Kale, Synthesis of photocatalytic $\mathrm{TiO}_{2}$ thin films via the high-pressure crystallization process at low temperatures, J. Hazard. Mater. 147 (2007) 213-218.

[4]. H.C. Lee, W.S. Hwang, Substrate effects on the oxygen gas sensing properties of $\mathrm{SnO}_{2} / \mathrm{TiO}_{2}$ thin films, Appl. Surf. Sci. 253 (2006) 1889-1897.

[5]. L. Sang, Y. Zhao, C. Burda, $\mathrm{TiO}_{2}$ nanoparticles as functional building blocks, Chem. Rev. 114 (2014) 9283-9318.

[6]. J. Xu, L. Li, Y. Yan, H. Wang, X. Wang, X. Fu, G. Li, Synthesis and photoluminescence of welldispersible anatase $\mathrm{TiO}_{2}$ nanoparticles, J. Colloid Interf. Sci. 318 (2008) 29-34.

[7]. K. Nagaveni, G. Sivalingam, M.S. Hegde, G. Madras, Solar photocatalytic degradation of dyes: high activity of combustion synthesized nano $\mathrm{TiO}_{2}$, Appl. Catal., B Environ. 48 (2004) 83-93.

[8]. S. Yin, Q. Zhang, F. Saito, T. Sato, Preparation of visible light-activated titania photocatalyst by mechanochemical method, Chem. Lett. 32 (2003) 358-359.

[9]. D.C. Hurum, A.G. Agrios, K.A. Gray, T. Rajh, C. Thurnauer, Explaining the enhanced photocatalytic activity of degussa P25 mixed-phase $\mathrm{TiO}_{2}$ using EPR, J. Phys. Chem. B 107 (2003) 4545-4549.

[10]. T. Luttrell, S. Halpegamage, J. Tao, A. Kramer, E. Sutter, M. Batzill, Why is anatase a better photocatalyst than rutile? - Model studies on epitaxial $\mathrm{TiO}_{2}$ films, Sci. Rep. 4 (2014) 4043.

[11]. H. Ogawa, T. Higuchi, A. Nakamura, S. Tokita, D. Miyazaki, T. Hattori, T. Tsukamoto, Growth of TiO 2 thin film by reactive RF magnetron sputtering using oxygen radical, J. Alloy. Compd. 449 (2008) 375 378.

[12]. M. Grätzel, Sol-gel processed $\mathrm{TiO}_{2}$ films for photovoltaic applications, J.Sol-Gel Sci. Technol. 22 (2001) 7-13.

[13]. C.C. Trepalis, P. Keivanidis, G. Kordas, M. Zaharescu, M. Crisan, A. Szatvanyi, M. Gartner, $\mathrm{TiO}_{2}\left(\mathrm{Fe}^{3+}\right)$ nanostructured thin films with antibacterial properties, Thin Solid Films 433 (2003) 186.

[14]. A. Rachel, M. Subrahmanyam, P. Boule, Comparison of photocatalytic efficiencies of $\mathrm{TiO}_{2}$ in suspended and immobilised form for the photocatalytic degradation of nitrobenzenesulfonic acids, Appl. Catal., B Environ. 37 (2002) 301. 
[15]. S. Senthilkumaar, K. Porkodi, R. Vidyalakshmi, Photodegradation of a textile dye catalyzed by sol-gel derived nanocrystalline $\mathrm{TiO}_{2}$ via ultrasonic irradiation, J. Photochem. Photobiol., A Chem. 170 (2005) 225.

[16]. P.A. Christensen, T.P. Curtis, T.A. Egerton, S.A.M. Kosa, J.R. Tinlin, Photoelectrocatalytic and photocatalytic disinfection of E. coli suspensions by titanium dioxide, Appl. Catal., B Environ. 41 (2003) 371.

[17]. K. Sunada, T. Watanabe, K. Hashimoto, Studies on photokilling of bacteria on $\mathrm{TiO}_{2}$ thin film, J. Photochem. Photobiol., A Chem. J. Photochem. Photobiol., A Chem. 156 (2003) 227.

[18]. A. Mills, A. Lepre, N. Elliott, S. Bhopal, I.P. Parkin, S.A. O'Neill, Characterisation of the photocatalyst Pilkington Activ ${ }^{\mathrm{TM}}$ : a reference film photocatalyst? J. Photochem. Photobiol., A Chem. 160 (2003) 213.

[19]. A. Mills, G. Hill, S. Bhopal, I.P. Parkin, S.A. O'Neill, Thick titanium dioxide films for semiconductor photocatalysis, J. Photochem. Photobiol., A Chem. 160 (2003) 185.

[20]. J.G. Yu, H.G. Yu, B. Cheng, X.J. Zhao, J.C. Yu, W.K. Ho, The effect of calcination temperature on the surface microstructure and photocatalytic activity of $\mathrm{TiO}_{2}$ thin films prepared by liquid phase deposition, J. Phys. Chem. B 107 (2003)13871-13879.

[21]. D. Mardare, M. Tasca, M. Delibas, G.I. Rusu, On the structural properties andoptical transmittance of $\mathrm{TiO}_{2}$ r.f. sputtered thin films, Appl. Surf. Sci. 156(2000) 200-206.

[22]. W. Zhang, S. Zhu, Y. Li, F. Wang, Photocatalytic property of $\mathrm{TiO}_{2}$ films deposited by pulsed DC magnetron sputtering, J. Mater. Sci. Technol. 20(2004) 31-34.

[23]. S. Daviosdottir, R. Shabadi, A.C. Galca, I.H. Andersend, K. Dirscherl, R. Ambata, Investigation of DC magnetron-sputtered $\mathrm{TiO}_{2}$ coatings: effect of coatingthickness, structure, and morphology on photocatalytic activity, Appl. Surf. Sci. 313 (2014) 677-686.

[24]. V. Pore, A. Rahtu, M. Leskela, M. Ritala, T. Sajavaara, J. Keinonen, Atomic layer deposition of photocatalytic $\mathrm{TiO}_{2}$ thin films from titanium tetramethoxideand water, Chem. Vap. Depos. 10 (2004) 143-148.

[25]. M. Miki-Yoshida, V. Collins-Martinez, P. Amèzaga-Madrid, A. Aguilar-Elguèzabal, Thin films of photocatalytic $\mathrm{TiO}_{2}$ and $\mathrm{ZnO}$ deposited inside a tubing by spray pyrolysis, Thin Solid Films 419 (2002) 60.

[26]. A. Mills, N. Elliott, I.P. Parkin, S.A.O. Neill, R.J. Clark, Novel $\mathrm{TiO}_{2}$ CVD films for semiconductor photocatalysis, J. Photochem. Photobiol., A Chem. 151 (2002) 171. 
[27]. O.J. Jung, S.H. Kim, K.H. Cheong, W. Li, S.J. Saha, Metallorganic Chemical Vapor Deposition and Characterization of $\mathrm{TiO}_{2}$ Nanoparticles, Bull. Korean Chem. Soc. 24 (2003) 49.

[28]. G.A. Battiston, R. Gerbasi, A. Gregori, M. Porchia, S. Cattarin, G.A. Rizzi, PECVD of amorphous $\mathrm{TiO}_{2}$ thin films: effect of growth temperature and plasma gas composition, Thin Solid Films 371 (2000) 126131.

[29]. K. Baba, S. Bulou, M. Quesada-Gonzalez, S. Bonot, D. Collard, N.D. Boscher, P. Choquet, Significance of a noble metal nanolayer on the UV and visible light photocatalytic activity of anatase $\mathrm{TiO}_{2}$ thin films grown from a scalable PECVD/PVD approach, ACS Appl. Mater. Interfaces 9 (2017) $41200-41209$.

[30]. K. Baba, S. Bulou, P. Choquet, N.D. Boscher, Photocatalytic anatase $\mathrm{TiO}_{2}$ thin films on polymer optical fiber using atmospheric-pressure plasma, ACS Appl. Mater. Interfaces 9 (2017) 13733-13741.

[31]. M. Maeda, T. Watanabe, Evaluation of photocatalytic properties of titanium oxide films prepared by plasma-enhanced chemical vapor deposition, Thin Solid Films 489 (2005) 320-324.

[32]. V. Rico, P. Romero, J.L. Hueso, J.P. Espinós, A.R. González-Elipe, Wetting angles and photocatalytic activities of illuminated $\mathrm{TiO}_{2}$ thin films, Catal. Today 143 (2009) 3470-354.

[33]. A. Dorian, H. Hanaor, C.C. Sorrell, Review of the anatase to rutile phase transformation, J. Mater. Sci. $46(2011) 855-874$.

[34]. A. Kolouch, P. Hájková, A. Macková, M. Horáková, J. Houdková, P. Špatenka, S. Hucek, Photocatalytic $\mathrm{TiO}_{2}$ thin Film Prepared by PE CVD at low Temperature, Plasma Process. Polym. 4 (2007) S350-S355.

[35]. D. Li, M. Carette, A. Granier, J. P. Landesman, A. Goullet, Effect of ion bombardment on the structural and optical properties of $\mathrm{TiO}_{2}$ thin films deposited from oxygen/titanium tetraisopropoxide inductively coupled plasma, Thin Solid Films 589 (2015) 783.

[36]. D. Li, S. Elisabeth, A. Granier, M. Carette, A. Goullet, J. P. Landesman, Structural and optical properties of $\mathrm{PECVD} \mathrm{TiO}_{2}-\mathrm{SiO}_{2}$ mixed oxide films for optical applications, Plasma Process. Polym. 13 (2016) 918-928.

[37]. W.G. Lee, S.I. Woo, J.C. Kim, S.H. Choi, K.H. Oh, Preparation and properties of amorphous $\mathrm{TiO}_{2}$ thin films by plasma enhanced chemical vapor deposition, Thin Solid Films 237 (1994) 105.

[38]. L. Martinu, D. Poitras, Plasma deposition of optical films and coatings: A review, J. Vac. Sci. Technol., A $18(2000) 2619$. 
[39]. M.L. Hitchman, K.F. Jensen, Chemical vapor deposition: principles and applications, Academic Press, London, 1993.

[40]. H. Szymanowski, O. Zabeida, J.E. Klemberg-Sapieha, L. Martinu, Optical properties and microstructure of plasma deposited $\mathrm{Ta}_{2} \mathrm{O}_{5}$ and $\mathrm{Nb}_{2} \mathrm{O}_{5}$ films, J. Vac. Sci. Technol., A 23 (2005) 241.

[41]. S. Larouche, H. Szymanowski, J.E. Klemberg-Sapieha, L. Martinu, S.C. Gujrathi, Microstructure of plasma-deposited $\mathrm{SiO}_{2} / \mathrm{TiO}_{2}$ optical films, J. Vac. Sci. Technol. A 22 (2004) 1200.

[42]. A.M. Wróbel, Surface free energy of plasma-deposited thin polymer films, in: K.L. Mittal (Ed.), Physicochemical Aspects of Polymer Surfaces, vol. 1, Plenum Press, New York, 1981, p. 197.

[43]. J. Behnisch, J. Tyczkowski, M. Gazicki, I. Pela, A. Holländer, R. Ledzion, Formation of hydrophobic layers on biologically degradable polymeric foils by plasma polymerization, Surf. Coat. Technol. 98 (1998) 872.

[44]. Y. Wang, E.C. Benck, M. Misakian, M. Edamura, J.K. Olthoff, Time-resolved measurements of ion energy distributions and optical emissions in pulsed radio-frequency discharges, J. Appl. Phys. 87 (2000) 2114.

[45]. M. Heintze, M. Magureanu, M. Kettlitz, Mechanism of $\mathrm{C}_{2}$ hydrocarbon formation from methane in a pulsed microwave plasma, J. Appl. Phys. 92 (2002) 7022.

[46]. S. Elisabeth, Ph.D. Thesis, University of Nantes, France, 2015.

[47]. N.D. Boscher, S. Olivier, R. Maurau, S. Bulou, T. Sindzingre, T. Belmonte, P. Choquet, Photocatalytic anatase titanium dioxide thin films depositionby an atmospheric pressure blown arc discharge, Appl. Surf. Sci. $311(2014) 721-728$.

[48]. A. Mills, J. Wang, Simultaneous monitoring of the destruction of stearic acid and generation of carbon dioxide by self-cleaning semiconductor photocatalytic films, J. Photoch. Photobio. A 182 (2006) 181186.

[49]. P. Stadelmann-JEMS Java Electron Microscopy Software-http://cime.epfl.ch/ (2004).

[50]. T. Ohsaka, F. Izumi, Y. Fujiki, Raman spectrum of anatase, $\mathrm{TiO}_{2}$, J. Raman Spectrosc. 7 (1978) 321324.

[51]. D.A.H. Hanaor, I. Chironi, I. Karatchevtseva, G. Triani, C.C. Sorrell, Single and mixed phase $\mathrm{TiO}_{2}$ powders prepared by excess hydrolysis of titanium alkoxide, Adv. Appl. Ceram. 111 (2012) 149-158. 
[52]. R. Maurau, N.D.Boscher, S. Olivier, S. Bulou, T. Belmonte, J. Dutroncy, T. Sindzingre, P. Choquet, Atmospheric pressure, low temperature deposition of photocatalytic $\mathrm{TiO}_{\mathrm{x}}$ thin films with a blown arc discharge, Surf. Coat. Technol. 232 (2013) 159-165.

[53]. A. Mills, A. Lepre, N. Elliott, S. Bhopal, I.P. Parkin, S.A. O’Neill, Characterisation of the photocatalyst Pilkington ActivTM: a reference film photocatalyst? J. Photoch. Photobio. A 160 (2003) 213-224

[54]. J.B. Chemin, S. Bulou, K. Baba, C. Fontaine, T. Sindzingre, N.D. Boscher, P. Choquet, Transparent anti-fogging and self-cleaning $\mathrm{TiO}_{2} / \mathrm{SiO}_{2}$ thin films on polymer substrates using atmospheric plasma, Sci. Rep. 8 (2018) 9603. 